\title{
Starch graft copolymers as superabsorbents obtained via reactive extrusion processing
}

\author{
Magdalena Zdanowicz, Beata Schmidt, Tadeusz Spychaj \\ Westpomeranian University of Technology in Szczecin, Polymer Institute, 70-322 Szczecin, ul. Pulaskiego 10, Poland, \\ e-mail: Tadeusz.Spychaj@zut.edu.pl
}

\begin{abstract}
Starch graft copolymers have been obtained via grafting of acrylic monomers i.e. acrylamide (AAm) and acrylic acid (AA) during the reactive extrusion processes. 2,2'-azobis (2-methylpropionamidine) dihydrochloride (AAPH) was used as a radical initiator and $\mathrm{N}^{\prime} \mathrm{N}$-methylenebisacrylamide (MBA), mixture of pentaerythritol triacrylate and pentaerythritol tetraacrylate (trade name PETIA) and alkoxylated pentaerithritol acrylate (trade name Ebecryl 40) were applied as acrylic crosslinkers. The obtained materials were characterized by FTIR and their water sorption properties investigated using swelling (vol. \%) and sorption (wt. \%) tests. Sorption of water into these graft copolymer samples reached values of ca. $6-13 \mathrm{~g}$ of water per $\mathrm{g}$ of dry materials. It was also found that water sorption values were dependent on ratio of AAm and AA as well as on a type of the applied crosslinking agent.
\end{abstract}

Keywords: superabsorbents, acrylamide, acrylic acid, starch modification, acrylic crosslinkers, reactive extrusion, starch graft copolymers.

\section{INTRODUCTION}

Development of plastics industry in the last decades has positively influenced many aspects of human life (the improvement of living standards, introduction novel light materials with wide spectra of applications), but on the other side also generates relevant problems with polymeric waste management. Annual production of plastics has exceeded 200 million tons. After fulfilling their function waste plastics become a nonbiodegradable ballast for the environment ${ }^{1}$. Application of natural biodegradable polymers can be a partial solution of environmental problems.

Starch is biorenewable, natural polymer that can be applied in plastics industry. It can be used as a filler (in a granular form) or after plasticization as a component of composite materials, blends or copolymers. Starch can be modified on chemical, physical or enzymatic way. Generally, physical modification leads at least to partial degradation of polysaccharide chains, which affects an increase of the products solubility in water. Physical modification can be carried out, for example, by using sonication, irradiation, plasticization in conjunction with thermal effects. Chemical modification of starch relies on the reactivity of hydroxyl groups and/or introduction of new functional groups into polysaccharide chains thus changing starch properties. For example, reduction, oxidation, esterification or etherification are processes giving new products with wide spectrum of applications ${ }^{2}$.

This work presents results of graft copolymerisation of potato starch with hydrophilic acrylic monomers in a presence of acrylic multifunctional crosslinkers during twin-screw extrusion processes. During starch graft copolymerisation active radicals are generated on backbone chain of polysaccharide, and then polymerization of monomers as side acrylic chains proceeds.

Starch graft copolymerization can be carried out in batch reactors or via reactive extrusion processing. Extruders, especially twin-screw extruders, manage with heat and mass transfer problems (e.g. dramatic viscosity of the reaction medium increases in batch polymerization processes).
Reactions performed in extruders have many advantages in comparison with batch operations. Reactive extrusion is an effective, dynamic process enabling minimizing or complete eliminating of solvents, less consumption of water, effective and homogenous mixing as well as shorter reaction time ${ }^{3,4}$. For example, comparable effects can be obtained for grafting acrylonitrile on starch both in batch reactor (time reaction was about 2 hours) and in twin screw extruder (couple of minutes) ${ }^{5}$. Another monomers applied for starch grafting are e.g.: methyl methacrylate ${ }^{6,7}$, or hydrophilic ones: acrylic acid ${ }^{8}$, acrylamide ${ }^{9}$, or itaconic acid ${ }^{7}{ }^{10}$. Starch presence in such copolymers facilitates and accelerates their degradation in the environment, and hydrophilicity of monomers enables access for microorganisms to polysaccharide copolymer chains. Literature concerning to the degradation of polyacrylamide (PAAm) in the environment is rather poor. There is a lack of data about the polymer degradation on microbiological way, and low molecular substances evolved to environment. There is one announcement that PAAm could be a source of nitrogen for some types of microorganisms (bacteria Entherobacter agglomonas and Azomonas macrocytogens) $)^{\mathbf{1 1}, \mathbf{1 2}}$.

Starch graft copolymers have many applications such as flocculants, oils recuperating agents and superabsorbents, important from point of view the environmental protection.

Superabsorbents are mainly used for production of materials absorbing the living body systemic liquids, as bioadhesive agents in pharmacology, as well as in the agriculture and gardening, as moisture immobilizing agents or fertilizer systems component, enzyme immobilizers and biosorbents in chromatography?

\section{EXPERIMENTAL}

\section{Material}

Graft copolymerization by the use of acrylic monomers was performed onto potato starch by reactive extrusion using co-rotating twin-screw extruder PRISM Eurolab 16 
Digital, Great Britain. Grafting monomers: acrylic acid ( $\sim 98 \%$, Fluka) and acrylamide (99\%, Aldrich) were used in a weight ratio 1:2 and 2:1 with summary weight ratio of the monomers to starch 0.3:1. Multifunctional crosslinking agents: $\mathrm{N}, \mathrm{N}$-methylenebisacrylamide (MBA, 99\%, Aldrich), mixture of penthaerythritol triacrylate and pentaerythritol tetraacrylate (PETIA, Cytec) and tetrafunctional alkoxylated tetraacrylate (Ebecryl 40, Cytec) were used. Amount of distilled water was 50/100 parts by weight of starch. Crosslinking agents were added in $0.5 \mathrm{wt} . \%$ according to starch amount. Copolymerizations were operated with varied extrusion screw speed rotations: 60,90 and $120 \mathrm{rpm}$. Starch was fed into feeding zone in an amount either $5.6 \mathrm{~g} / \mathrm{min}$ or $6.6 \mathrm{~g} / \mathrm{min}$. Temperature profile along the extruder from feeding to die was: 88/115/100/80/60/60/60/60/60/60 for starch graft copolymers with monomers weight ratio $\mathrm{AAm} / \mathrm{AA}=2: 1$ (for all crosslinking agents) and $\mathrm{AAm} / \mathrm{AA}=1: 2$ with PETIA crosslinker, or $80 / 115 / 100 / 60 / 50 / 50 / 50 / 50 / 50$ for $\mathrm{AAm} / \mathrm{AA}=1: 2$ with MBA and Ebecryl 40. Scheme of the applied extruder is presented in Figure 1.

The monomers were dissolved in distilled water and fed by pump to zone 1 of the extruder processing section. An aqueous solution of initiator: 2,2'-azobis(2-methyl propionamidine) dihydrochloride - AAPH (0.1 wt.\%, based on starch; 97\%, Aldrich, water-soluble azo compound generating free radicals during thermal decomposition) was fed into feeding zone of the extruder. Received extrudate was left for on about $12 \mathrm{~h}$ at ambient temperature, and then shredded in a pelletiser (PRISM VARICUT 16).

\section{PROCEDURE AND APPARATUS}

\section{Water sorption properties}

Starch copolymer granulates were ground by a knife mill and sieved. For tests, the fraction under $0.30 \mathrm{~mm}$ was collected. Water sorption tests were made with the $0.5 \mathrm{~g}$ sample in $50 \mathrm{~cm}^{3}$ volume of distilled water at room temperature. After 30 minutes a suspension with the swollen sample was filtered, then weighted and water sorption determined.

$\mathbf{W}=\left[\left(\mathbf{m}_{\mathrm{a}}-\mathbf{m}_{\mathrm{d}}\right) / \mathbf{m}_{\mathrm{d}}\right] * 100 \%$

$\mathrm{W}$ - water sorption [wt.\%]

$\mathrm{m}_{\mathrm{a}}$ - sample weight after sorption $[\mathrm{g}]$

$\mathrm{m}_{\mathrm{d}}-$ dry sample weight $[\mathrm{g}]$.

Another method evaluation of swellability was also performed. It was based on volume changes before and after water sorption (vol.\%). The $0.5 \mathrm{~g}$ sieved copolymer sample $\left(1 \mathrm{~cm}^{3}\right)$ was placed into $25 \mathrm{~cm}^{3}$ measuring cylinder and distilled water was added. After 30 minutes swollen volume of the copolymer sample was determined.

$\mathbf{P}=\left(\mathrm{V}_{\mathrm{m}} / \mathbf{V}_{\mathrm{s}}\right) * 100 \%$

$\mathrm{P}$ - swelling degree [vol.\%]

$\mathrm{V}_{\mathrm{m}}$ - volume of swollen sample $\left[\mathrm{cm}^{3}\right]$

$\mathrm{V}_{\mathrm{s}}$ - volume of dry sample $\left[\mathrm{cm}^{3}\right]$.

\section{Fourier transform infrared spectroscopy}

Infrared spectra for the obtained starch graft copolymers were measured by Fourier transform infrared spectroscopy. Representative samples in pulverized form were put in spectrometer Nexus FTIR, fitted with Golden Gate attenuated total reflection (ATR) accessory (Thermo Nicolet Corp., USA). Spectra FTIR were worked out by using OMNIC software.

\section{RESULTS AND DISCUSSION}

Results of water sorption measurements were collected in the Table 1. Table 1 presents: (i) data from sorption tests in wt. \% for copolymer samples manufactured at 60 , 90 and $120 \mathrm{rpm}$ for two starch feed rates, i.e. 5.6 and 6.6 $\mathrm{g} / \mathrm{min}$, and (ii) data from swelling tests in vol. \% for the copolymer extrudates obtained at $90 \mathrm{rpm}$ and for a starch feed rate $6.6 \mathrm{~g} / \mathrm{min}$. The obtained results show that higher values of weight sorption have been found for starch graft copolymers with weight ratio of monomers AAm/AA 2:1. The highest values of weight sorption are achieved by those with a mixture of tri- and tetrafunctional acrylate (PETIA) - up to $1280 \mathrm{wt} . \%$. The lowest values of that parameter are found when difunctional crosslinker was used - up to $710 \mathrm{wt} . \%$. Results of copolymers swellabilities lay in a range of $420-600 \mathrm{vol} . \%$. The highest value is for PETIA crosslinking agent again. However, no influence of the crosslinker nor comonomer ratio was confirmed. Higher content of AAm in copolymers (weight ratio AAm/ $\mathrm{AA}=2: 1$ ) corresponds higher values of water sorption, regardless of used crosslinking agent. Grafted AAm branches increase hydrophilic character of the starch graft copolymer due to strong H-bonding between polymer chains containing acrylamide units.

When compared the crosslinker type, the highest values of the respective parameters were obtained for PETIA (up to $1280 \mathrm{wt} . \%$ ) and the lowest for MBA (up to 710 wt.\%). Graphic specification of water sorption values for the selected copolymer samples (obtained at 60 and 120 rpm of screw speeds) are presented in Figure 2A and B.

Table 1 also presents swelling rate in vol. $\%$ for samples extruded at $90 \mathrm{rpm}$ and $6.6 \mathrm{~g} / \mathrm{min}$ starch feed. Sorption

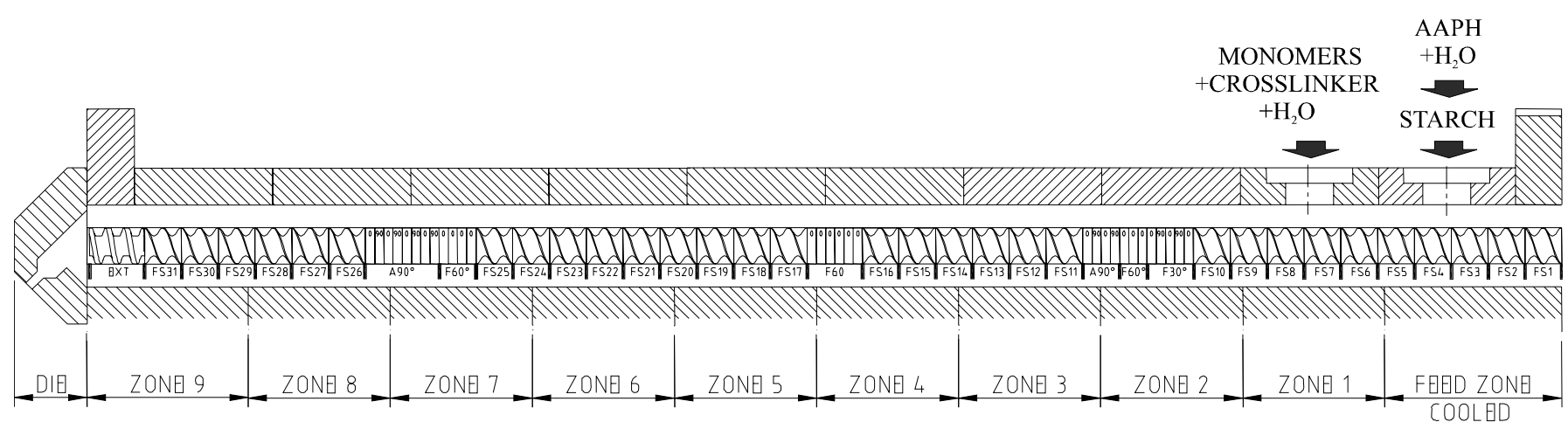

Figure 1. Scheme of the twin-screw extruder with marked feeding zones 
Table 1. Range of water sorption for starch/AAm/AA grafted copolymers with various crosslinking agents, and screw speeds: 60, 90, $120 \mathrm{rpm}$ (monomers weight ratio to starch 0.3:1)

\begin{tabular}{|c|c|c|c|c|c|c|}
\hline \multirow{2}{*}{ AAm/AA wt./wt. } & \multicolumn{4}{|c|}{ Crosslinking agent } & \multicolumn{3}{c|}{ Ebecryl 40} \\
\cline { 2 - 7 } & wt. $\%$ & vol. $\%^{*}$ & wt. $\%$ & PEI. \%* & wt. \% & vol. \%* \\
\cline { 2 - 7 } & $660-710$ & 450 & $910-1280$ & 600 & $890-1020$ & 500 \\
\hline $2: 1$ & $660-710$ & 470 & $680-840$ & 550 & $620-920$ & 420 \\
\hline $1: 2$ & &
\end{tabular}

*samples obtained for screw speed $90 \mathrm{rpm}$ and starch doze $6.6 \mathrm{~g} / \mathrm{min}$
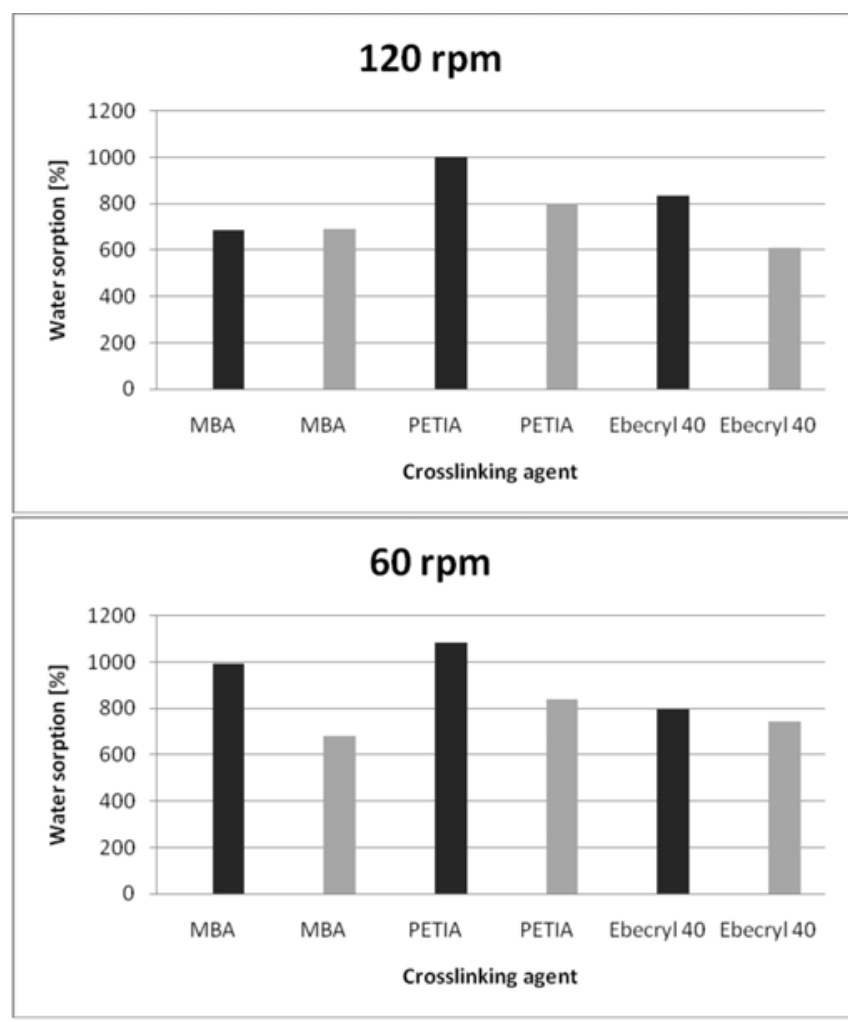

$-\operatorname{starch} / \mathrm{AAm}: \mathrm{AA}=2: 1$
$-\operatorname{starch} / \mathrm{AAm} / \mathrm{AA}=1: 2$

Figure 2. Water sorption values for samples with varied monomers weight ratio and various crosslinkers, obtained at extruding parameters: screw speed 120 $\mathrm{rpm}(\mathrm{A})$ and $60 \mathrm{rpm}(\mathrm{B})$, starch dose $6.6 \mathrm{~g} / \mathrm{min}$

volume measurements exhibit similar dependences like in case of the weight sorption tests. The highest value was received when PETIA crosslinker (600 vol.\%) was used. Values of swellability for graft copolymers synthesized of $\mathrm{AAm} / \mathrm{AA}=2: 1$ were higher than for $\mathrm{AAm} / \mathrm{AA}=1: 2$ in case of applied PETIA and Ebecryl 40 crosslinkers. Comparing sorption values, significant influence of screw speed on the sorption properties was not observed (Table 1 contains ranges of sorption results). An order of increasing water sorption properties (from both tests) depending on the applied crosslinking agent is:

PETIA > Ebecryl $40>$ MBA

The differences of water sorption properties of starch graft copolymers can be related to structure and molecular weights of the multifunctional crosslinkers. A weight ratio of the particular crosslinking agent was the same in all cases $(0.5 \mathrm{wt}$. \% on monomers) but the molar content was different. The highest molar amount was used in case of MBA (0.97 mmole) with the lowest molecular weight (154.2 g/mole). Average apparent molecular weight of PETIA is higher (325.4 g/mole). It does mean that for crosslinking starch/AAm/AA copolymer 0.43 mmole of the apparent compound was used. Alkoxylated pentaerythritol tetraacrylate Ebecryl 40 has the highest molecular weight $(571 \mathrm{~g} / \mathrm{mole})$ but their applied molar amount was the lowest and equal 0.26 mmole. It can be concluded that amount and chain lengths of applied crosslinkers can affect crosslinking density finally determining water retention. The higher crosslinks densities the smaller free space for retraining water molecules. The lowest water sorption has been found for the copolymers crosslinked with tetrafunctional MBA. On the other hand PETIA was used in molar amount ca. two times lower than MBA. Additionaly pentraerythritol triacrylate - one of the PETIA components - has hydroxyl group in its structure that can interact with water molecule. Higher water sorption values for Ebecryl 40 crosslinked starch/AAm/AA copolymers in comparison to those with MBA can be connected with its high molar mass and long chain branches of the polyether acrylate.

Qualitative FTIR analysis allows to observe polymer modification. Infrared spectroscopy displayed effective grafting of monomers onto polysaccharide chain (Fig. 3). Spectra exhibited wide waveband ranged from $3650-3200 \mathrm{~cm}^{-1}$ indicating presence of hydroxyl groups, and peak for $2900 \mathrm{~cm}^{-1}$ relating stretching oscillations C-H group. Both of them are typical spectra for unmodified starch and starch graft copolymers with AA and AAm. Characteristic bands appeared in wavenumbers $1700-1500 \mathrm{~cm}^{-1}$, which don't exist in unmodified starch. These bands are caused by oscillations: stretching carboxyl and amide groups introduced to graft copolymer chains. It confirmed starch modification via grafting.

\section{CONCLUSIONS}

Starch graft copolymers with hydrophilic acrylic monomers can be applied as potential water superabsorbents. Sorption values of starch/AAm/AA copolymers - products of the reactive extrusion process ranged from 600 to almost $1300 \mathrm{wt}$. \%. The sorption properties changed with a type of applied crosslinking agent. The highest sorption was found for copolymers crosslinked by mixture of pentaerythritol triacrylate and pentaerythritol tetraacrylate (trade name PETIA) and the lowest for materials with N,N'-methylenebisacrylamide. Swelling degree (in volume \%) roughly correlates with the water sorption results (in weight \%).

\section{ACKNOWLEDGEMENTS}

The work is performed in a frame of research project $\mathrm{N}$ 505241033 financed by Ministry of Science and Higher Education. 


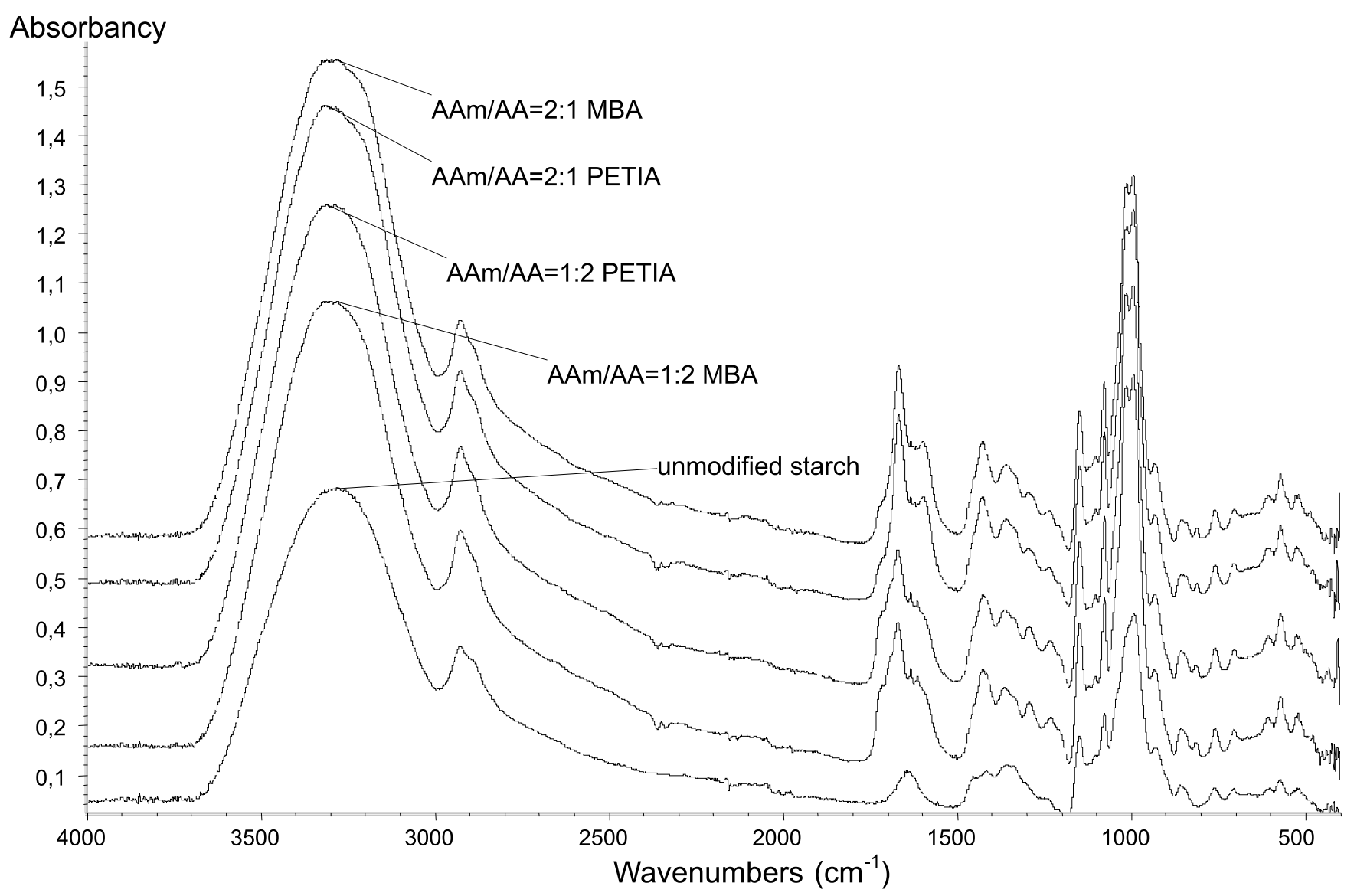

Figure 3. FTIR spectra of the crosslinked starch graft copolymers with crosslinking agents: MBA, PETIA; monomers weight ratio $\mathrm{AAm} / \mathrm{AA}=2: 1$ and $\mathrm{AAm} / \mathrm{AA}=1: 2$ and unmodified starch

\section{LITERATURE CITED}

1. Scheirs, J. (1998). Polymer recycling. Science technology and applications. J. Willey \& Sons, Chichester.

2. Tomasik, P. (2000). Modified starches and their application (in Polish). Przemyst Spożywczy. 54(4), 16 - 18.

3. Raquez, J.M., Narayan, R. \& Dubois, P. (2008). Recent advances in reactive extrusion processing of biodegradable polymer-based compositions. Macromol. Mat. Eng. 293(6), 447 - 470. DOI: 10.1002/mame.200700395.

4. Xie, F., Yu, Long., Liu, H. \& Chen, Ling. (2006). Starch modification using reactive extrusion. Starch. 58, 131 - 139, DOI: 10.1002/star.200500407.

5. Yoon, K.J., Carr, M.E. \& Bagley, E.B. (1992). Reactive extrusion vs. batch preparation of starch-g-polyacrylonitrile J. Appl. Polym. Sci. 45(6), 1093 - 1100.

6. Bravo-Osuna, I., Ferrero, C. \& Jimenez-Castellanos, M.R. (2005). Water sorption-desorption behavior of methyl methacrylate-starch copolymers: effect of hydrophobic graft and drying method. European Journal of Pharmaceutics and Biopharmaceutics. 59(3), 537 - 548. DOI: 10.1016/ j.ejpb.2004.10.003.

7. Tomasik, P., Fiedorowicz, M. \& Para, A. (2004). Novelties in chemical modification of starch, in Starch: progress in structural studies, modifications. Kraków: Polish Society of Food Technologists - Małopolska Branch, pp. 301 - 331.

8. Athawale, V.D. \& Vidyagauri L. (1998). Graft copolymerization onto starch. II. Grafting of acrylic acid and preparation of it's hydrogels. Carboh. Polym. 35(1 - 2), $21-$ 27. DOI: 10.1016/s0144-8617(97)00138-p.

9. Finkenstadt, V.L. \& Willet, J.L. (2003). Preparation of starch-graft-polyacrylamide copolymers by reactive extrusion. Polym. Eng. Sci. 43(10), 1666 - 1674. DOI: 10.1002/pen.10140.

10. Lanthong, P., Nuisin, R. \& Kiatkamjornwong, S. (2006). Graft copolymerization, characterization, and degradation of cassava starch-g-acrylamide/itaconic acid superabsorbents.
Carboh. Polym. 66(2), 229 - 245. DOI:10.1016/ j.carbpol.2006.03.006.

11. Kay-Shoemake, G. I., Waterood, M.E., Lenz, R.D. \& Sojka, R.E. (1998). Polyacrylamide as an organic nitrogen source for soil microorganisms with potential effect on inorganic soil nitrogen in agricultural soil. Soil Biol. Biochem. 30(8/ 9), 1045 - 1052. DOI:10.1016/S0038-0717(97)00250-2.

12. Caulfield, J. M, Qiao., G.G. \& Solomon, D. H. (2002). Some aspects of the properties and degradation of polyacrylamides. Chem. Review. 102(9), 3067 - 3084. DOI: 10.1021/cr010439p. 